\title{
RANCANG BANGUN TRAINER DENGAN LCD LAYAR SENTUH MENGGUNAKAN ARDUINO MEGA 2560 SEBAGAI MEDIA PEMBELAJARAN PADA MATA KULIAH ELEKTRONIKA DIGITAL
}

\author{
Rosita Fitri Nur ${ }^{1, *}$, Jusuf Bintoro ${ }^{2}$, and Pitoyo Yuliatmojo ${ }^{3}$ \\ ${ }^{1}$ Mahasiswa Program Studi Pendidikan Teknik Elektronika, Fakultas Teknik-UNJ \\ ${ }^{2,3}$ Dosen Program Studi Pendidikan Teknik Elektronika, Fakultas Teknik - UNJ
}

\begin{abstract}
Abstrak. Penelitian ini merupakan jenis penelitian Research and Development $(\mathrm{R} \& \mathrm{D})$ yang bertujuan untuk mengembangkan trainer dengan LCD layar sentuh menggunakan Arduino Mega 2560 sebagai media pembelajaran pada mata kuliah Elektronika Digital yang meliputi; 1) Potensi dan masalah, 2) Pengumpulan data, 3)Desain produk, 4) Validasi desain, 5) Revisi Desain, 6) Ujicoba Produk, 7) Revisi Produk, 8) Ujicoba Pemakaian. Objek penelitian ini adalah trainer yang dilengkapi dengan modul praktikum elektronika digital. Metode yang digunakan dalam pengumpulan data pada penelitian ini meliputi pengujian dan pengamatan terhadap unjuk kerja trainer dengan LCD layar sentuh serta pengujian yang dilakukan dengan memberikan angket kepada 38 mahasiswa Pendidikan Teknik Elektronika Universitas Negeri Jakarta. Uji kelayakan media pembelajaran di uji oleh ahli materi dan ahli media. Hasil pengembangan media terdiri dari trainer dengan LCD layar sentuh yang berisi 3 modul rangkaian digital yaitu modul gerbang logika, modul flip-flop dan modul rangkaian kombinasional. Hasil penelitian menunjukan persentase kelayakan media diperoleh sebesar 94,64\% dari ahli materi, 96,96\% dari ahli media, dan 84,5\% dari hasil ujicoba terhadap mahasiswa. Dari ketiga perolehan tersebut, media pembelajaran ini masuk dalam kategori sangat layak untuk digunakan sebagai media pembelajaran pada mata kuliah Elektronika Digital di program studi Pendidikan Teknik Elektronika Universitas Negeri Jakarta..

Kata Kunci: Trainer, LCD Layar Sentuh, Arduino Mega 2560
\end{abstract}

\begin{abstract}
This research type is Research and Development $(R \& D)$ that aimed to develop a trainer with LCD touch screen using Arduino Mega 2560 as a learning media in Digital Electronics subjects which consists of; 1) Potential and problems, 2) Data retrieval, 3) Product design, 4) Product validation, 5) Design revision, 6) Product trial, 7) Product trial, and 8)Usage Trial.. The object of this field is a trainer equipped with a digital electronics practicum module. The method that used in collecting data in
\end{abstract}

${ }^{*}$ Corresponding author: roshitafit $97 @$ gmail.com 


\begin{abstract}
this field was testing and observing the performance of trainer with LCD touch screen and testing conducted by giving questionnaires to 38 students of Electronics Engineering Education Study Program, Jakarta State University. The feasibility test of media learning was tested by material and media experts. The result of media development is a trainer with $L C D$ touch screen which contains of 3 digital circuit modules, namely a logic gate module, a flip-flop module and a combinational circuit module. The results showed that the percentage of media feasibility was obtained $94.64 \%$ from material experts, $96.96 \%$ from media experts, and $84.5 \%$ from the results of trials on students. From this acquisition, this media learning is very feasible to be used as a media learning of Digital Electronics subject in Electronics Engineering Education study program at State University of Jakarta.
\end{abstract}

Keyword: Trainer, LCD Touch Screen, Arduino Mega 2560

\title{
1 Pendahuluan
}

Hasil belajar peserta didik dipengaruhi oleh beberapa faktor. Menurut faktor-faktor yang mempengaruhi hasil belajar peserta didik banyak jenisnya. Salah satu faktor yang mempunyai pengaruh cukup besar dalam pencapaian hasil belajar merupakan media pembelajaran (Slameto, 2003:54).[1]

Menurut Asosiasi Pendidikan Nasional (National Education Association/NEA) dalam Sadiman (2009: 7) menjelaskan bahwa "media adalah bentuk-bentuk komunikasi baik tercetak maupun audiovisual serta peralatannya. Media hendaknya dapat dimanipulasi, dapat dilihat, didengar dan dibaca". Media pembelajaran meliputi perangkat keras (hardware) dan perangkat lunak (software). Hardware adalah alat-alat yang dapat mengantarkan pesan seperti overhead projector, radio, televisi dan sebagainya. Sedangkan software adalah isi program yang mengandung pesan seperti informasi yang terdapat pada transparansi atau buku dan bahan-bahan cetak lainnya, cerita yang terkandung dalam film atau materi yang disuguhkan dalam bentuk bagan, grafik, diagram, dan lainnya.[2]

Salah satu bentuk dari media pembelajaran adalah alat pembelajaran atau juga disebut trainer. Alat Pembelajaran merupakan bagian dari jenis media pembelajaran yang dapat menyalurkan pesan yang akan disampaikan kepada peserta didik (Gerlach, 1980: 5).[3]

Peraturan Menteri Riset, Teknologi, dan Pendidikan Tinggi Republik Indonesia Nomor 44 tahun 2015 Tentang Standar Nasional Pendidikan Tinggi Bagian Ketujuh Standart Sarana dan Prasarana Pembelajaran pasal 32 ayat 1 menyatakan "Standar sarana pembelajaran sebagaimana dimaksud dalam Pasal 31 paling sedikit terdiri atas: a) Perabot; b) Peralatan pendidikan; c) Media pendidikan; d) Buku, buku elektronik, dan repositori; e) Sarana teknologi informasi dan komunikasi; f) Instrumentasi eksperimen; g) Sarana olahraga; h) Sarana berkesenian; i) Sarana fasilitas umum; j) Bahan habis pakai; dan k) Sarana pemeliharaan, keselamatan, dan keamanan.

Para ahli memiliki pandangan perbandingan pemerolehan hasil belajar melalui indera pandang dan indera dengar sangat menonjol perbedaannya. Kurang lebih $90 \%$ hasil belajar seseorang diperoleh melalui indera pandang dan hanya sekitar 5\% diperoleh melalui indera dengar dan 5\% lagi dengan indera lainnya menurut Baugh dalam Arsyad (2009:10). Sementara itu, Dale memperkirakan bahwa pemerolehan hasil belajar melalui hasil belajar memalui indera pandang berkisar $75 \%$ melalui indera dengar sekitar $13 \%$ dan melalui indera lainnya sekitar $12 \%$.[4]

Pemahaman pengembangan media pembelajaran elektronika digital dengan kepesatan teknologi sangat penting sebagai proses pembelajaran contohnya penggunaan LCD layar sentuh dan Arduino Mega 2560. LCD (Liquid Crystal Display) layar sentuh adalah sebuah perangkat input komputer yang bekerja dengan adanya sentuhan tampilan layar 
menggunakan jari atau pena digital. Antarmuka layar sentuh, dimana pengguna mengoperasikan sistem komputer dengan menyentuh gambar atau tulisan di layar itu sendiri, merupakan cara yang paling mudah untuk mengoperasikan komputer dan kini semakin banyak digunakan dalam berbagai aplikasi. Pengendalian LCD layar sentuh dapat menggunakan mikrokontroler Arduino Mega 2560. Fungsi dari Arduino adalah suatu chip atau IC (Integrated Circuit) yang bisa di program menggunakan komputer. Program yang direkam bertujuan agar rangkaian elektronik dapat membaca input, memproses, dan kemudian menghasilkan output sesuai yang diinginkan. Penggunaan LCD layar sentuh dengan kendali mikrokontroler Arduino Mega 2560 dapat dijadikan sebagai media yang menarik karena pengoperasian cara kerjanya memiliki tampilan yang dapat menarik perhatian mahasiswa sehingga dapat meningkatkan pemahaman dan penguasaan dengan materi yang akan dipraktikan.

Berdasarkan hasil pengamatan peneliti, pada kegiatan perkuliahan mata kuliah Elektronika Digital Program Studi Pendidikan Teknik Elektronika UNJ, mahasiswa mengalami keterbatasan media dan efektivitas waktu yang masih kurang. Kompetensi pada mata kuliah tersebut perlu dioptimalkan proses pembelajarannya agar mahasiswa dapat memiliki pemahaman mendasar untuk perkuliahan dan siap memasuki dunia pekerjaan. Kurangnya alat bantu pembelajaran yang disediakan oleh perguruan tinggi menjadi salah satu pemicu rendahnya minat belajar mahasiswa terutama dalam kegiatan praktikum. Pemanfaatan media pembelajaran trainer belum dimaksimalkan oleh dosen pengampu dan mahasiswa di Program Studi Pendidikan Teknik Elektronika karena pelaksanaan kegiatan praktikum dengan alat bantu yang ada pada laboratorium kurang bervariasi karena mahasiswa tidak menggunakan lembar kerja atau jobsheet pada saat proses pembelajaran dan ketersediaan komponen elektronika digital yang terbatas.

\section{METODOLOGI PENELITIAN}

Metode penelitian dan pengembangan atau dalam Bahasa Inggris Research and Development adalah metode penelitian yang digunakan untuk menghasilkan produk tertentu, dan menguji keefektifan produk tersebut [5]. Langkah-langkah penelitian dan pengembangan ditunjukan pada Gambar 1.[5]

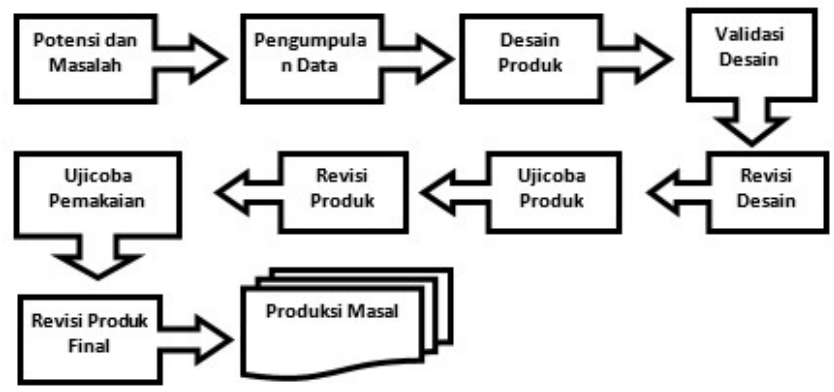

Gambar 1. Langkah-Langkah Penggunaan Metode Research and Development

Berikut diagram blok dari trainer dengan LCD layar sentuh pada Gambar 2. 


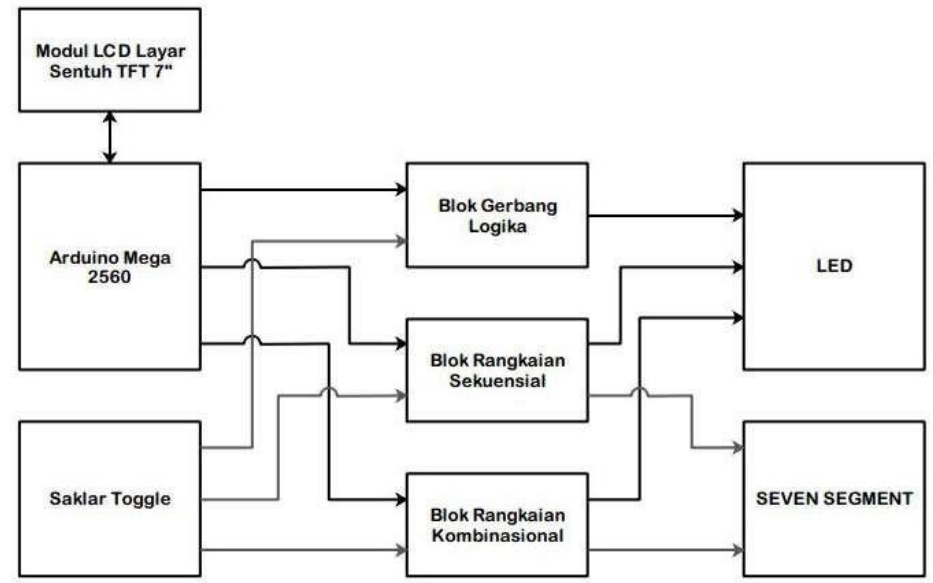

Gambar 2. Diagram Blok Trainer Dengan LCD Layar Sentuh

\subsection{Teknik Analisis Data}

Analisis data yang digunakan untuk penelitian pengembangan media pembelajaran elektronika digital yaitu teknik analisis deskriptif kuantitatif. Teknik analisis deskriptif kuantitatif adalah memaparkan produk media hasil rancangan media setelah diimplementasikan daam bentuk produk jadi dan menguji tingkat kelayakan produk. Data kualitatif yang didapatkan kemudian diubah menjadi data kuantitatif dengan teknik pengukuran yang digunakan dalam pengumpulan data adalah menggunakan skala likert.

Menurut Sugiyono (2012: 193), skala likert memiliki dari sangat positif sampai sangat negatif yang dapat diwujudkan dalam beragam kata-kata jawaban, yang dalam penelitian ini meliputi: Sangat Setuju (SS), Setuju (S), Tidak Setuju (TS), dan Sangat Tidak Setuju (STS). Kemudian dalam analisis kuantitatid maka jawaban yang ada dikonversikan dalam bentuk tingkatan bobor skor nilai yang digunakan sebagai skala pengukuran yaitu : 4, 3, 2, dan 1 . Data instrumen penelitian yang diperoleh dan dikonversikan kedalam data kuantitatif, kemudian dengan melihat bobot tiap tanggapan yang dipilih atas tiap tanggapan yang dipilih atas pernyataan. Data yang telah diperoleh kemudian dicari skor rata-ratanya dengan rumus:

$$
\bar{x}=\frac{\sum x}{n}
$$

$$
\begin{aligned}
& \text { Keterangan : } \\
& \bar{x} \quad=\text { skor rata-rata } \\
& n \quad=\text { jumlah penilai } \\
& \sum x=\text { skor total masing-masing }
\end{aligned}
$$

Kemudian untuk menghitung tingkat persentase kelayakan media digunakan rumus seperti berikut:

$$
\text { persentase kelayakan }(\%)=\frac{\text { skor hasil instrumen }}{\text { skortotal instrumen }} \quad 100 \%
$$

Jika ini persentase rerata didapat maka selanjutnya adalah menunjukkan predikat kualitas dari produk yang dibuat berdasarkan skala pengukuran rating scale. Saka penunjukan rating scale adalah pengubahan data kualitatis menjadi kuantitatif. Tabel 1. merupakan rating scale yang digunakan untuk penafsiran kelayakan pada produk penelitian. 
Tabel 1. Kategori Kelayakan Berdasarkan Rating Scale

\begin{tabular}{|l|c|c|}
\hline No. & Skor dalam Persen $(\%)$ & Kategori Kelayakan \\
\hline 1. & $0-25 \%$ & Sangat Tidak Layak \\
\hline 2. & $>25 \%-50 \%$ & Kurang Layak \\
\hline 3. & $>50 \%-75 \%$ & Cukup Layak \\
\hline 4. & $>75 \%-100 \%$ & Sangat Layak \\
\hline
\end{tabular}

\section{Hasil dan Pembahasan}

\subsection{Validasi Ahli Materi}

Validasi ahli materi dilakukan untuk penilaian materi pada mata kuliah Elektronika Digital yang mencakup beberapa aspek, yaitu aspek edukatif dan aspek teknis. Pada Gambar 3. menunjukkan rekapitulasi hasil validasi ahli materi pada setiap aspek penilaian.

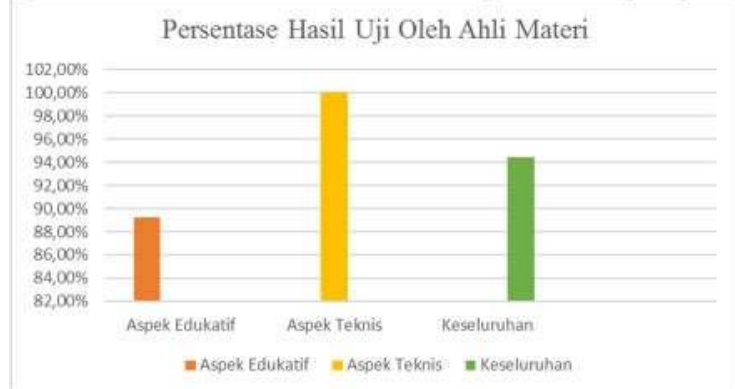

Gambar 3. Diagram Hasil Validasi Ahli Materi Setiap Aspek

Berdasarkan Gambar 3. diperoleh data kelayakan ditinjau dari aspek kuantitas materi yang didapat dari ahli materi yaitu $94,64 \%$. Dengan menggunakan rating scale untuk mengubah data kuantitatif menjadi kualitatif, maka trainer dengan LCD layar sentuh dikategorikan sangat layak untuk digunakan sebagai media pembelajaran Elektronika Digital pada Program Studi Pendidikan Teknik Elektronika UNJ.

\subsection{Validasi Ahli Media}

Validasi ahli media dilakukan untuk penilaian terkait situs media pembelajaran untuk mata kuliah Elektronika Digital yang meliputi beberapa aspek, yaitu aspek teknis dan aspek tampilan. Pada Gambar 4. menunjukkan rekapitulasi dari hasil validasi ahli media pada setiap aspek penilaian.

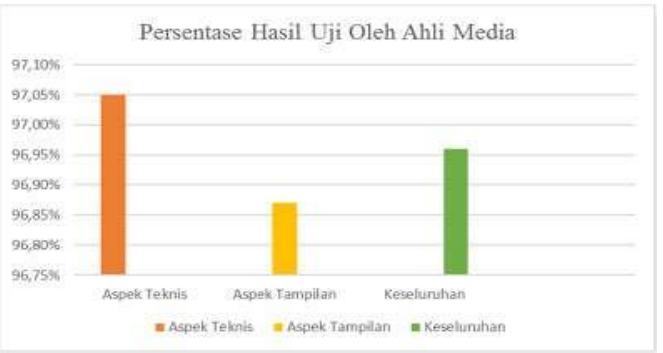

Gambar 4. Diagram Hasil Validasi Ahli Media Setiap Aspek 
Dilihat dari Gambar 4. diperoleh data kelayakan media pembelajaran dari ahli media ditinjau dari aspek teknis yaitu 97,05\%. Sedangkan ditinjau dari aspek tampilan sebesar $96,07 \%$. Perolehan nilai kelayakan secara keseluruhan yang diperoleh dari ahli media adalah sebesar 96,96\%. melihat perolehan nilai keseluruhan yang didapat dari ahli media, maka media pembelajaran ini dapat dikategorikan sangat layak dalam rating scale untuk digunakan sebagai media pembelajaran mata kuliah Elektronika Digital.

\subsection{Efektifitas Produk}

Uji pemakaian media pembelajaran dilakukan kepada pengguna sebagai validitas eksternal yaitu mahasiswa yang mengambil Mata Kuliah Elektronika Digital Program Studi Pendidikan Teknik Elektronika Universitas Negeri Jakarta dengan jumlah responden. Penilaian ditinjau dari tiga aspek yaitu aspek kualitas edukatif (materi), aspek teknis, dan aspek estetika (tampilan).

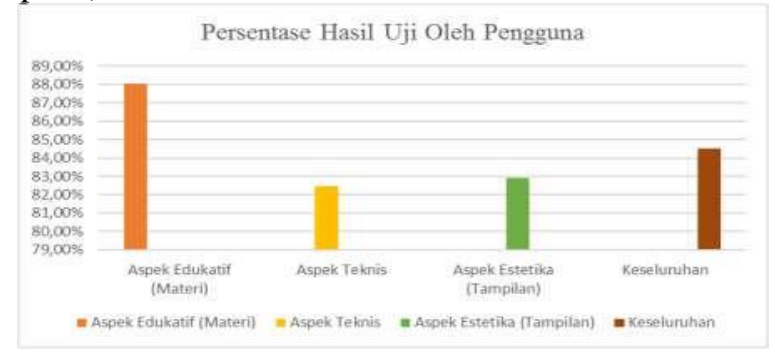

Gambar 5. Diagram Hasil Penilaian Siswa Setiap Aspek

Berdasarkan Gambar 5. persentase uji validasi pemakaian media oleh pengguna (validitas eksternal) di dapatkan nilai persentase kelayakan 84,5\%. Dengan demikian dapat disimpulkan bahwa media pembelajaran sangat layak pembelajaran di program studi Pendidikan Teknik Elektronika.

\section{Kesimpulan}

Kesimpulan secara singkat berdasarkan media pembelajaran modul dan trainer dengan LCD layar sentuh pada mata kuliah Elektronika Digital Program Studi Pendidikan Teknik Elektronika di Universitas Negeri Jakarta adalah sebagai media pembelajaran trainer dibuat dengan metode penelitian dan pengembangan (Research and Development) dengan 8 langkah 1) Potensi dan masalah, 2) Pengumpulan data, 3)Desain produk, 4) Validasi desain, 5) Revisi Desain, 6) Ujicoba Produk, 7) Revisi Produk, 8) Ujicoba Pemakaian. Media pembelajaran dibuat berdasarkan 2 tahap yaitu tahap pembuatan modul/jobsheet dan pembuatan trainer. Pembuatan media pembelajaran dibuat sesuai silabus mata kuliah Elektronika Digital di Program Studi Pendidikan Teknik Elektronika, Universitas Negeri Jakarta. Pengujian kelayakan konstruk yang dilakukan oleh Ahli Media memperoleh presentase penilaian sebesar $96,96 \%$ yang artinya produk sangat layak. Pengujian kelayakan isi yang dilakukan oleh Ahli Materi memperoleh presentase penilaian sebesar $94,64 \%$ yang artinya produk sangat layak. Pengujian penggunaan produk dilakukan oleh 38 mahasiswa sebagai pengguna yang telah mengikuti mata kuliah Elektronika Digital Program Studi Pendidikan Teknik Elektronika Universitas Negeri Jakarta. Dari hasil penilaian pengguna yang dilakukan oleh mahasiswa memperoleh presentase penilaian sebesar $84.5 \%$ yang artinya produk sangat layak. 


\section{Daftar Pustaka}

1. Slameto. Belajar dan Faktor-faktor yang Mempengaruhinya. Jakarta. PT. Rineka Cipta. (2003).

2. A. Sadiman, Media Pendidikan: Pengertian, Pengembangan dan Pemanfaatannya. Jakarta: PT. Rajagrafindo Persada. (2003).

3. Gerlach, D.P. Ely. Multimedia Learning: Prinsip-prinsip dan Aplikasi. Yogyakarta. Pustaka Pelajar. (1980)

4. A. Arsyad. Media Pembelajaran. Jakarta: PT. Rajagrafindo Persada. (2009)Sugiyono, Metode Penelitian Kuantitatif, Kualitatif, dan R\&D. Bandung. CV Alfabeta, (2009) 